\title{
CAMA
}

Centre for Applied Macroeconomic Analysis

\section{Time-Varying Effect of Oil Market Shocks on the Stock Market}

\section{CAMA Working Paper 35/2015 August 2015}

Wensheng Kang

Department of Economics, Kent State University, Ohio, USA

\section{Ronald A. Ratti}

School of Business, University of Western Sydney, NSW, Australia and

Centre for Applied Macroeconomic Analysis (CAMA), ANU

\section{Kyung Hwan Yoon}

School of Business, University of Western Sydney, NSW, Australia

\section{Abstract}

A mixture innovation time-varying parameter VAR model is used to examine the impact of structural oil price shocks on U.S. stock market return. Time variation is evident in both the coefficients and the variance-covariance matrix. The standard deviations of the demand side structural shocks reached forty year peaks during the global financial crisis and have remained high since. In the real stock return equation the coefficient of global real economic activity has declined since the late 1990s and that of oil-market specific demand oil shock has been lower since the early 1990s than before. The structural oil shocks account for $25.7 \%$ of the long-run variation in real stock returns overall, with substantial change in levels and sources of contribution over time. The contribution of shocks to global real economic activity to real stock return variation rose sharply to $22 \%$ in 2009 (and remains 17\% over 2009-2012). The contribution of oil-market specific demand price shocks rose unevenly from $5 \%$ in the mid-1970s to about $15 \%$ in 2007 , with a subsequent decline. The contribution of oil supply shocks has trended downward from $17 \%$ to $5 \%$ over $1973-2012$. 


\section{Keywords}

mixture innovation, oil shocks, real stock return, time-varying parameter VAR

\section{JEL Classification}

E44, G10, Q41, Q43

\section{Address for correspondence:}

(E) cama.admin@anu.edu.au

The Centre for Applied Macroeconomic Analysis in the Crawford School of Public Policy has been established to build strong links between professional macroeconomists. It provides a forum for quality macroeconomic research and discussion of policy issues between academia, government and the private sector.

The Crawford School of Public Policy is the Australian National University's public policy school, serving and influencing Australia, Asia and the Pacific through advanced policy research, graduate and executive education, and policy impact. 


\title{
Time-Varying Effect of Oil Market Shocks on the Stock Market
}

\author{
by \\ Wensheng Kang ${ }^{\mathrm{a}^{*}}$, Ronald A. Ratti ${ }^{\mathrm{bc**}}$, Kyung Hwan Yoon ${ }^{\mathrm{b} * * *}$, \\ ${ }^{a}$ Department of Economics, Kent State University, Ohio, USA \\ ${ }^{\mathrm{b}}$ School of Business, University of Western Sydney, NSW, Australia \\ ${ }^{\mathrm{c} C e n t r e ~ f o r ~ A p p l i e d ~ M a c r o e c o n o m i c ~ A n a l y s i s, ~ A N U, ~ A u s t r a l i a ~}$
}

\begin{abstract}
A mixture innovation time-varying parameter VAR model is used to examine the impact of structural oil price shocks on U.S. stock market return. Time variation is evident in both the coefficients and the variance-covariance matrix. The standard deviations of the demand side structural shocks reached forty year peaks during the global financial crisis and have remained high since. In the real stock return equation the coefficient of global real economic activity has declined since the late 1990s and that of oil-market specific demand oil shock has been lower since the early 1990s than before. The structural oil shocks account for $25.7 \%$ of the long-run variation in real stock returns overall, with substantial change in levels and sources of contribution over time. The contribution of shocks to global real economic activity to real stock return variation rose sharply to 22\% in 2009 (and remains 17\% over 2009-2012). The contribution of oil-market specific demand price shocks rose unevenly from $5 \%$ in the mid1970 s to about $15 \%$ in 2007 , with a subsequent decline. The contribution of oil supply shocks has trended downward from $17 \%$ to $5 \%$ over $1973-2012$.

JEL classifications: E44, G10, Q41, Q43

Key words and phrases: mixture innovation, oil shocks, real stock return, time-varying parameter VAR

\footnotetext{
*Wensheng Kang; Department of Economics, Kent State University, Ohio, US; Tel. No: +1 330-308-7414; E-mail address wkang3@kent.edu

** Corresponding author: Ronald A. Ratti; University of Western Sydney, School of Business, Australia; Tel. No: +61 29685 9346; E-mail address: r.ratti@uws.edu.au

Kyung Hwan Yoon; University of Western Sydney, School of Business, Australia; Tel. No: +61 29685 9067; Email address: k.yoon@uws.edu.au
} 


\section{Time-Varying Effect of Oil Market Shocks on the Stock Market}

\section{Introduction}

Hamilton (2013) notes that major change has taken place in the global oil market since the early 1970s with fluctuations in the real price of oil, movement in the sources of demand for oil, and shifts in oil production due to geopolitical events, changes in economic motivations, technologies, and resources. Baumeister and Peersman (2013a) demonstrate that the volatility of the real price of crude oil has been higher since 1986 and that the volatility of global oil production has trended downwards over the last thirty five years.

Blanchard and Gali (2009) argue that there has been a change in the causal relationship between oil price and the economy, in that increases in oil price are linked with smaller movements in output and inflation in recent years than in the 1970s. Blanchard and Riggi (2013) document that these changes are due to more efficient use of oil, lower real wage rigidity, and better monetary policy. It has been noted by a number of researchers that there has been structural change over time in the macroeconomy. Sims and Zha (2006) find that the variance of the exogenous shocks has changed overtime and Primiceri (2005) and Koop et al. (2009) find that in addition, the parameters connecting the variables have also evolved over time. In an analysis of the commodity market, Narayan et al. (2013) find that commodity (including oil) market profits are regime dependent and contingent on structural breaks. In the literature review it is noted that much of the oil price-stock return literature finds structural shifts, time varying volatility, and changes and nonlinearity in the relationship between oil prices and stock returns over time.

In this paper we investigate changes in the variance of the structural shocks in the crude oil market over time and in the transmission of oil market shocks to the U.S. stock market over 
time. If oil price shocks have changed over time and have changing effects on the real economy through consumer and firm behavior, then there should be changing observable effects of oil price shocks on the stock market. The evolving relationships between structural oil price shocks and stock market return are examined using a time-varying structural vector autoregression (VAR) model.

Bayesian estimation of the time-varying VAR model is developed based on Koop et al. (2009) in which both the transmission mechanism and the error covariance matrix can change over time. ${ }^{1}$ The change in parameters overtime is modeled based on the mixture innovation method of Gerlach et al. (2000) and Giordani and Kohn (2008), that is regarded as a special Bayesian stochastic search approach to selecting restrictions for VAR models. Cogley and Sargent (2005), Primiceri (2005) and Baumeister and Peersman (2013b) also estimate a VAR model with stochastic volatility and time variation in both the coefficients and the variancecovariance matrix, but unlike Koop et al. (2009) place restrictions on the time variation of the parameters and use sign restrictions when generating impulse responses.

The structural form VAR model is based on that in Kilian and Park (2009), the first paper to recognize that in examination of the connection between crude oil prices and the stock market it is important to identify global influences that might drive both. Kilian and Park (2009) show that increased global real economic activity is associated with rising oil price and a rising U.S. stock market, and that oil price increases driven by oil-market specific demand shocks, identified by controlling for global demand for commodities and supply disruptions, cause the U.S. stock market to fall.

\footnotetext{
${ }^{1}$ Koop and Korobilis (2010) provide an extensive survey of the Bayesian methods used in modern empirical macroeconomics.
} 
With the mixture innovation time-varying parameter VAR model, alteration in the relationships between oil market shocks and stock market return can be observed and connected to changes in transmission of oil market shocks to the stock market and to transformation in the nature of the structural shocks in the oil market over time. A benefit of the approach is that parameters change endogenously over time (or do not change over time) in line with the data. ${ }^{2}$

In the Bayesian time-varying structural VAR model it is found that coefficients and the nature of shocks have changed over time. In the global real economic activity equation the standard deviation of residuals has fluctuated over time, reaching a forty year peak during the global financial crisis (GFC) and remaing high since. The standard deviation of residuals in the oil-market specific demand equation have been rising since the mid-1980s with peak value during the GFC. The standard deviation of residuals in the global oil production equation are smaller since the mid-1990s than before. In the real stock return equation, the posterior coefficient of global real economic activity has declined since the late 1990s, that of global oil production has remained stable, and that of oil price increases driven by oil-market specific demand shocks have fluctuated, being relatively high before 1988 and lower afterwards, especially from 1995 to 2001 and since 2006.

The contribution of oil supply shocks to real stock return variation in the U.S. after 24 months has trended downward over time from 17\% in 1973 to 5\% in 2012, in line with relatively unchanging oil supply coefficients in the real stock return equation and decling standard deviation of residuals in the global oil production equation. The contribution of oil-market specific demand price shocks to real stock return variation gradually rose unevenly from the

\footnotetext{
${ }^{2}$ Sims (1980) notes the virtue in the data providing information on changes in parameters rather than with economic theory forcing hard restrictions and yielding unsatisfactory results. The issue of parameter instability and of structural breaks has been considered by Miller and Ratti (2009) for effects of oil prices on stock markets and Blanchard and Gali (2009) for effects of oil prices on the economy, but with the restriction of only allowing changes in parameters at a small number of points in time.
} 
order of $5 \%$ in the mid-1970s to about $15 \%$ in 2007 , with a subsequent decline. The rise in contribution to real stock return variation up until 2007 is in line with the increase in the standard deviation of residuals in the oil-market specific demand equation since the mid-1980s.

The contribution of shocks to global real economic activity to real stock return variation fluctuates in the $5 \%$ to $12 \%$ range from $1973-2008$, before rising steeply to $22 \%$ in 2009 and remaining above $17 \%$ over 2009-2012. This is consistent with sharply higher standard deviation of residuals in the global aggregate demand equation during and following the GFC.

The negative cummulative response of US real stock return to a positive oil marketspecific demand shock, builds up (in absolute value) over three months and then persists relatively unchanged for 24 months. The correlation between simultaneous and subsequent cummulative responses to oil market-specific demand shock is high. The positive cummulative response of US real stock return to a global aggregate demand shock builds up over twelve months and then persists relatively unchanged up to 24 months. The cummulative response of US real stock return to an oil supply shock has been relatively small at all monthly horizons since the mid-1990s.

In the empirical work on the Bayesian estimation of the time-varying structural VAR model we investigate how important the changes of parameters have been on results through the analysis of impulse response functions, where the sources of time variation are both the coefficients and the variance covariance matrix of the innovations. Our study presents robust results using both empirical Bayes priors and noninformative priors in the analysis.

The paper is organized as follows. A literature review of work on the effect of oil prices on stock returns is presented in Section 2. Section 3 presents the time-varying structural VAR 
model. Section 4 describes the data. Section 5 discusses empirical results on the dynamics of global oil price shocks and stock market and presents robustness results. Section 6 concludes.

\section{Literature review}

Following work by Chen et al. (1986) and Jones and Kaul (1996) identifying oil price as a risk factor for stock price, a substantial body of work has examined the effect of the price of oil on stock returns. Work reporting that oil price increases lead to reduced stock returns includes Sadorsky (1999) for the U.S., Nandha and Faff (2008) for global industry indices, and Park and Ratti (2008) for U.S. and European oil importing countries. Aloui et al. (2013) find positive conditional dependence between crude oil price and stock markets in the transition economies of Central and Eastern Europe. The literature has provided a wide range of possible connections between oil price and stock markets. Jiménez-Rodríguez and Sanchez (2005) argue that the negative effects for oil importing countries are reinforced because of intensive trade connections. Aloui et al. (2012) consider the effects of oil price shocks on stock returns in emerging markets classified as heavily oil dependent, moderately oil-dependent, and net-oil exporting. Phan et al. (2015a) investigate the differential effect of oil shocks on the stock returns of oil producing and oil consuming firms. Guesmi et al. (2014) examine the volatility spill over between the stock returns of oil exporting and importing countries. Arouri et al. (2012) show significant volatility spillovers between oil price and sector stock returns in Europe. Elder and Serletis (2010) examine the connection between oil price uncertainty and financial and macroeconomic indicators.

The literature has reported findings that the relationship between oil prices and stock returns changes over time. Sim and Zhou (2015) argue the effects of oil price shocks on stock returns are contingent on the performance of the US stock market and the sign and size of these 
shocks. Chang and Yu (2013) show that the impacts on stock return of oil price shocks are regime-dependent (as between turbulent and stable periods). Inchauspe et al. (2015) estimate an asset pricing model with time-varying coefficients and find that oil price has become more influential in influencing stock returns after 2007. Chen (2010) estimates time-varying transitionprobability Markov-switching models and shows that higher oil prices increases the probability of a bear market in stock prices. Moya-Martínez et al. (2014) investigate the role of endogenous structural change in the connection between oil price changes and Spanish sector stock returns and find that the relationship is more marked during the 2000s than in the 1990s. Chang et al. (2013) find little evidence of volatility spillovers between the crude oil and financial markets, but find that conditional correlations are not constant within markets.

Jiménez-Rodríguez (2015) investigates non-linearity in the relationship between oil prices and stock markets in several advanced economies and finds it important to control for the time-varying conditional variability of the oil price shocks. Broadstock and Filis (2014) show that correlations between oil price shocks and stock returns are time-varying. Jouini (2013) finds a nonlinear long-run relationship between Gulf Cooperation Countries' stock markets and movements of global factors including oil price. Lee and Zeng (2011) find that the performance (especially extreme performance) of stock markets affects the impact of oil price shocks on real stock returns. Arouri (2011) estimates linear and asymmetric models of the connection between oil and European stock prices and finds that results differ across sectors. Arouri and Rault (2011) find that large oil price changes have a positive impact on stock returns in oil-exporting countries.

The literature concerned with forecasting oil prices and stock returns, evaluates out-ofsample forecasts on the basis of updated and time-varying estimates, and provides further motivation for an analysis of the time-variation in the relationship between oil prices and stock 
returns. Phan et al. (2015b) report that oil price out-of-sample forecasts of returns of stock returns perform well and are affected by frequency of the data, the estimator employed, and the characteristics of the stock sector being considered. Narayan and Sharma (2014) find that oil price provides significant out-of-sample forecasts of the variance of firm returns. Panopoulou and Pantelidis (2015) present evidence that use of regime-switching models provides better oil price forecasts than single regime models.

In recent papers analyzing the influence of oil prices on financial variables it is recognized as being essential to identify the underlying source of the oil price shocks. These papers and Kilian and Park (2009) build on the important contribution by Kilian (2009) emphasizing that oil price increases have very different effects on the real economy depending on whether change in oil price is driven by demand or supply shocks in the oil market. Hamilton (2009) argues that oil price increases in the several years before the GFC were mainly due to growth in developing markets and not associated with the negative consequences of supply-side disruption. Filis et al. (2011) find oil price increases occasioned by demand-side influence have a positive impact on stock market returns. Apergis and Miller (2009) find small effects of structural oil price shocks on stock market returns in a number of developed countries, and Abhyankar et al. (2013) find that the effects are significant in Japan. Degiannakis et al. (2014) show that a rise in price of oil associated with increased aggregate demand significantly raises stock market volatility in Europe. Cunado and de Gracia (2014) find a negative effect of oil price changes on most European stock market returns, particularly when driven by oil supply shocks.

\section{Methodology}

\subsection{The model}


In the model we start from a time-varying reduced-form VAR to time-varying structural form VAR in a standard way to identify the supply and demand shocks driving innovations in real price of oil over time and examine their effects on U.S. real stock returns in a time-varying framework. To specify the time-varying reduced-form VAR model we follow Koop et al. (2009) to begin with a state space model in which the sources of time variation are both the coefficients in the model and the variance covariance matrix of the innovations. The measurement equation is given by,

$$
y_{t}=z_{t} \alpha_{t}+\varepsilon_{t}
$$

and the state equation is given by,

$$
\alpha_{t+1}=\alpha_{t}+k_{1 t} \eta_{t}
$$

where $y_{t}$ is a $m \times 1$ vector of endogenous variables, $z_{t}=\left(c_{t}, y_{t-1}, \ldots y_{t-p}\right)$ stands for a $m \times(p+1)$ matrix of data on explanatory variables where $p$ denotes the appropriate lag length of the endogenous variables, $\alpha_{t}=\left(\alpha_{0, t}, \alpha_{1, t}, \ldots, \alpha_{p, t}\right)^{\prime}$ represents the coefficients, and $\varepsilon_{t} \quad N\left(0, H_{t}\right)$ is the error term in the measurement equation and $\eta_{t} \quad N(0, Q)$ the error term in the state equation. In the empirical analysis, the endogenous variables $y_{t}$ takes 6 lags $(p=6)$ determined by Akaike information criteria (AIC) and Bayes-Schwarz information criterion (BSC) in the reduced-form VAR model (1). This keeps the dimension of parameter space manageable and is consistent with much of the existing literature such as the choice of a lag length of 7 in Apergis and Miller (2009) and of 4 in Degiannakis et al. (2013). ${ }^{3}$

\footnotetext{
${ }^{3}$ In their linear (time-invariant) VAR models, Apergis and Miller (2009) and Degiannakis et al. (2013) make the selection of the optimal lag length determined by AIC and BSC. Narayan and Sharma (2011) confirm that there is strong evidence of lagged effect of oil price on firm returns.
} 
The elements of the error variance and covariance matrix $H_{t}=A_{t}^{-1} \Sigma_{t} \Sigma_{t}^{\prime}\left(A_{t}^{-1}\right)^{\prime}$ are allowed to change over time, where $\Sigma_{t}$ is a diagonal matrix and $A_{t}$ is a lower triangular matrix with diagonal elements equal to one. Let the elements of the diagonal matrix $\Sigma_{t}$ be $\ln \sigma_{t}=\left(\ln \sigma_{1 t}, \ldots, \ln \sigma_{m t}\right)^{\prime}$ in the state equation,

$$
\ln \sigma_{t+1}=\ln \sigma_{t}+k_{2 t} \mu_{t}
$$

where $\mu_{t}$ is $N(0, W)$ and independent over $t$. We then stack the non-zero and non-one elements of the lower triangular matrix $A_{t}$ by rows into a $m(m-1) / 2$ vector as $a_{t}=\left(a_{21, t}^{\prime}, a_{31, t}^{\prime}, a_{32, t}^{\prime}, \cdots, a_{m(m-1), t}^{\prime}\right)^{\prime}$. The law of motion for the vector's elements is a driftless random walk,

$$
a_{t+1}=a_{t}+k_{3 t} \varsigma_{t},
$$

where $\varsigma_{t}$ is $N(0, S)$ and is independent over $t$.

In the above state space system (1) - (4), the variance covariance matrix of the innovations in the state equations (2), (3) and (4) are block diagonal,

$$
\left(\begin{array}{l}
\eta_{t} \\
\mu_{t} \\
\varsigma_{t}
\end{array}\right) \quad N\left(0,\left(\begin{array}{ccc}
Q & 0 & 0 \\
0 & W & 0 \\
0 & 0 & S
\end{array}\right)\right),
$$

that is $\eta_{t}, \mu_{t}$ and $\varsigma_{t}$ are independent over $t$ and independent of $\varepsilon_{t}$, and $Q, W$ and $S$ are positive definite matrices. Note that in the state equations (2), (3) and (4), the latent variables $k_{1 t}, k_{2 t}$ and $k_{3 t}$ are independent contemporaneously and at all lags and leads and take on the value of 1 if there is a change in the corresponding state errors and 0 otherwise. The probabilities of 
$k_{j t}, j=1,2,3$, being zero or one are assigned with a prior distribution and are subsequently updated from the data likelihood.

The mixture innovation specification allows for the estimation of the number of breaks that is based on data providing information on changes in the regression coefficients and the elements of variance-covariance matrix. In an extensive survey of macroeconomic models, Bauwens et al. (2014) show that recognition of the presence of structural breaks is of crucial importance for forecasting most macroeconomic time series. This approach is regarded as a special form of Bayesian model stochastic search method to selecting restrictions for VAR models (for example see George and McCulloch (1997), George et al. (2008), Jochmann et al. (2010), and Jochmann et al. (2013)).

\subsection{Priors}

In the empirical Bayesian analysis we follow Primiceri (2005), Koop et al. (2009) and Korobilis (2013) to use a training sample, the first 5 years of data, 1968:01-1972:12, to calibrate the key prior hyperparameters: $\quad \alpha_{0} \quad N\left(\hat{\alpha}_{0}, m(p+1) \times \hat{V}_{\alpha}\right), \quad \ln \left(\sigma_{0}\right) \quad N\left(\ln \left(\hat{\sigma}_{0}\right), I_{m}\right) \quad$ and $a_{0} \quad N\left(\hat{a}_{0}, m(m-1) \times \hat{V}_{a}\right)$, where $m=4$ the dimension of endogenous variable vector, $p=6$ the lag length in the VAR model, ${ }^{4} \hat{\alpha}_{0}$ and $\hat{V}_{\alpha}$ are conditional MLE estimates of the time-invariant VAR regression coefficients and their covaiance matrix respectively, $\hat{a}_{0}$ and $\hat{\sigma}_{0}$ are obtained by decomposing the error covariance matrix, $\Omega=A^{-1} \Sigma \Sigma^{\prime}\left(A^{-1}\right)^{\prime}$, and $\hat{V}_{a}$ is also obtained from the time-invariant VAR estimates of the variance covariance matrix of $\hat{a}_{0}$.

\footnotetext{
${ }^{4}$ The specification of 6-month lag length follows much of the literature on TVP-VAR models represented by Rotemberg and Woodford (1997), Cogley and Sargent (2001, 2005), Primiceri (2005), Koop et al. (2009), and Liu and Morley (2014) (that usually takes 2 quarterly lags).
} 
For the variance covariance matrices of the innovations in the state equations (2), (3) and (4), we utilize Wishart priors $Q^{-1} W\left(\underline{v}_{Q}, \underline{V}_{Q}^{-1}\right)$, where $\underline{v}_{Q}=m(p+1)+1$ and $\underline{V}_{Q}=0.05 \times m(p+1) \times I_{m(p+1)}, W^{-1} \quad W\left(\underline{v}_{w}, \underline{V}_{w}^{-1}\right)$, where $\underline{v}_{w}=m+1$ and $\underline{V}_{w}=0.0001 \times m \times I_{m}$, and $S^{-1} \quad W\left(\underline{v}_{S}, \underline{V}_{S}^{-1}\right)$, where $\underline{v}_{S}=m(m-1)+1$ and $\underline{V}_{S}=0.01 \times m(m-1) \times I_{m(m-1)}$. Here we choose small degree of freedom parameters in order to put a small weight on the priors that makes the priors to contain small amount of information relative to the sample.

To complete the model, the Beta prior of the form $p_{j} \quad \operatorname{Beta}(1,1), \quad j=1,2,3$, is placed on the hyper-parameters $k_{j t}, j=1,2,3$, respectively, to control the prior belief about the number of breaks through a non-informative choice. The advantageous feature allows us to deal with the unknown number of change points rather than impose the hard restriction for the break points; that is the prior expectation on the probabilities of $k_{j t}, j=1,2,3$, being zero or one is at an even break $\left(E\left(p_{j}\right)=0.5\right.$ and $\left.\operatorname{std}\left(p_{j}\right) \quad 0.29, j=1,2,3\right)$. The probability is subsequently updated from the data likelihood as a way of letting the data speak about how parameters evolve.

\subsection{Estimation}

The full conditional posterior distributions of all parameters of interest in the state-space model (1) - (4) are first drawn for the full sample T using the standard Markov chain Monte Carlo (MCMC) estimation algorithm. Conditional on $\alpha_{T}, \log \sigma_{T}$ and $a_{T}$, the time-varying elements $\alpha_{t}, \log \sigma_{t}$ and $a_{t}, t=1,2, \ldots, T-1$, are simulated by using backward recursions proposed by Carter and Kohn (1994) and Durbin and Koopman (2002) from three Gaussian linear state-space system separately. ${ }^{5}$

\footnotetext{
${ }^{5}$ See the detailed MCMC algorithm in the technical appendix of Primiceri (2005) and Koop et al. (2009). Recently, Del Negro and Primiceri (2014) have made a correction to the MCMC procedures in Primiceri (2005). We follow their updated procedures when we utilize Koop et al.’s (2009) method.
} 
Here we note only the sampling for the elements of variance-covariance matrix $H_{t}$ and the extra steps for the mixture innovation aspect of the model. Following Primiceri (2005) and Koop et al. (2009) we first draw stochastic volatility states $\log \sigma_{j t}$ separately for $j=1, \ldots, m$. Define $y_{t}^{*}=A_{t}\left(y_{t}-z_{t} \alpha_{t}\right)$ and let $y_{j t}^{* *}=\ln \left[\left(y_{j t}^{*}\right)+c\right]$ where $\mathrm{c}=0.001$ in a standard practice making it small and no effect on the derivation. We then obtain $y_{j t}^{* *}=2 \ln \sigma_{j t}+e_{j t}$ and its state Equation (3). The normal distribution of $e_{j t}, j=1, \ldots, m$, is approximated according to Kim et al. (1998) and the standard state space algorithm is applied to generate $\log \sigma_{t}$. Second, to sample the covariance states $a_{t}$, we define $\hat{y}_{t}=y_{t}-z_{t} \alpha_{t}$ and

$$
C_{t}=\left(\begin{array}{ccccccccc}
0 & & & & & & & 0 \\
-\hat{y}_{1 t} & 0 & 0 & & & & & \vdots \\
0 & -\hat{y}_{1 t} & -\hat{y}_{2 t} & 0 & & & & \\
0 & 0 & 0 & -\hat{y}_{1 t} & \ldots & & & \\
\vdots & & & & & 0 & \ldots & 0 \\
0 & \ldots & & & 0 & -\hat{y}_{1 t} & \ldots & -\hat{y}_{m-1, t}
\end{array}\right)
$$

We then obtain $\hat{y}_{t}=C_{t} a_{t}+\xi_{t}$, where $\xi_{t} N\left(0, \Sigma_{t} \Sigma_{t}\right)$ independent over $t$, and its state Equation (4). The standard state space algorithm is then applied to simulate $a_{t}$. Finally, we sample the regression coefficients $\alpha_{t}$ and the error variance covariance matrix $H_{t}$ using the state space system (1) and (2).

The parameters $k_{j t}, j=1,2,3$, are sampled using the algorithm of Gerlach et al. (2000) that is an efficient approach to modelling dynamic mixtures in that it generates $k_{j t}, j=1,2,3$, without conditioning on the states $\alpha_{t}$, $\log \sigma_{t}$ and $a_{t}$. Conditional on the value $k_{j t}, j=1,2,3$, in turn, each state equation (2), (3) or (4) has conditionally normal errors and standard state space algorithm can be used to estimate the time-varying parameters of interest. The simulation of 
hierarchical posterior $p_{j t}$ for $k_{j t}, j=1,2,3$, is based on $\operatorname{Beta}\left(v_{1 j}, v_{2 j}\right)$, where $v_{1 j}=1+\sum_{t=1}^{T} k_{j t}$ and $v_{2 j}=1+T-\sum_{t=1}^{T} k_{j t}$ for the breakpoint probabilities.

\subsection{The structural VAR representation}

Once the reduced-form VAR model (1) is consistently estimated in the above state space framework, the resulting estimates are then used to construct the structural VAR representation through the relationship, $\varepsilon_{t}=A_{t}^{-1} \Sigma_{t} u_{t}$, in the following:

$$
y_{t}=z_{t} \alpha_{t}+A_{t}^{-1} \Sigma_{t} u_{t}, u_{t} \quad N\left(0, I_{m}\right)
$$

where $\gamma_{t}=A_{t}^{-1} \Sigma_{t}$ imposes the identification restrictions to allow for the structural interpretation.

We assume that the first block of endogenous variables within $y_{t}$, in order, consists of the first difference of the natural logarithm of world oil production $\left(\Delta \operatorname{prod}_{t}\right)$, the first difference of global real aggregate demand $\left(\Delta r e a_{t}\right)$, and the first difference of the natural logarithm of real price of oil $\left(\Delta r p o_{t}\right)$. Kilian (2009) notes that this block captures the supply and demand conditions in the world oil market and attributes the fluctuation of oil prices to oil supply-side shocks, shocks to global aggregate demand and oil-market specific demand shocks. The supply of crude oil is inelastic in the short run, in the sense that the oil supply does not respond to contemporaneous changes in oil demand within a given month because of the high adjustment cost of oil production. The fluctuation of real prices of oil does not lower global real economic activity within a given month because of slow global real reaction.

The second block of endogenous variables within $y_{t}$ consists of U.S. real stock returns $\left(\right.$ ret $\left._{t}\right)$. In line with the standard approach of treating innovations to the price of oil as pretetermined with respect to the economy (e.g., Lee and Ni (2002)), we rule out instananeous responses from shocks to oil prices in the world oil market to the U.S. stock market. Recent 
studies by Kilian and Vega (2011) and Kang and Ratti (2013) find that there is no significant evidence of feedback within a given month from U.S. aggregates to the price of crude oil.

These identification assumptions imply that $\gamma_{t}=A_{t}^{-1} \Sigma_{t}$ is lower triangular, where the MCMC draws of $A_{t}$ and $\Sigma_{t}$ can be directly transformed to provide us with draws of $\gamma_{t}$. With the time-varying structural VAR representation, the macroeconomic features of interest can be

presented over time. For example, the impulse responses of real stock returns to oil supply/demand-side price shocks can be calculated for a structural shock at any time point $\tau$ based on the estimation of parameters as they are at time $\tau$.

\section{Data and test results}

The data in the empirical analysis on the crude oil market and stock market return are monthly over 1968:01 to 2012:12. The stock market return for the U.S. is from daily/monthly returns of aggregate U.S. stock market indices drawn from CRSP that represent a value-weighted market portfolio including NYSE, AMEX and Nasdaq stocks. Monthly real stock return is monthly nominal stock return adjusted by the change in U.S. CPI (from the U.S. Bureau of Labor Statistics).

The natural logrithm of the world crude oil production in millions of barrels per day averaged monthly from the U.S. Department of Energy is a proxy for oil supply. The real price of oil is the natural logrithm of refiner's acquisition cost of imported crude oil, obtained from the U.S. Department of Energy, deflated by the U.S. CPI. The refiner's acquisition cost of imported crude oil is available from January 1974. Following Barsky and Kilian (2002), we use the U.S. producer price index for oil (DRI code: PW561) and the composite index for refiner's acquisition cost of imported and domestic crude oil to extend the oil price data back to January 1968. 
Global economic activity is given by Kilian’s (2009) real aggregate demand index. ${ }^{6}$ This index is based on equal-weighted dry cargo freight rates, in the sense that a rise in the index indicates higher demand for shipping services driven by increased global economic activity. An advantage of the measure is that it is global and it reflects activity in such developing and emerging economies as China and India.

Figure 1 illustrates monthly return in the U.S. stock market over 1973:01-2012:12. The timing of the outbreak of major historical events causing higher oil prices is marked in the figure. Examination of Figure 1 shows that oil shocks caused by well-known prominent geopolitical events in history (e.g., oil embargo in 1934-1974, Iranian Revolution in 1978-1979, Iraq War in 2003, oil spike in 2008 and Arab Spring in 2011) are closely associated with large fluctuations in the U.S. stock market.

Figure 2 shows the evolution of the time-varying unconditional standard deviation of the world oil production, real refiners' acquisition cost of imported crude oil, and real stock market returns, estimated based on 5-year rolling windows, in the U.S. over 1973:01 - 2012:12. ${ }^{7}$ The volatility of world oil production shows larger fluctuations in the early part of the sample before the mid-1990s and becomes smaller and stable over recent periods. While the amplitude of real oil price volatility has increased significantly since the late 1980s, real U.S. stock market return has exhibited larger fluctuations since the early 1990s. As is evident from both figures, the changes in oil market dynamics over time appear to be associated with the concurrent large fluctuations in the U.S. stock market.

\footnotetext{
${ }^{6}$ The data is available at http://www-personal.umich.edu/ lkilian/paperlinks.html.

${ }^{7}$ Efimova and Serletis (2014) provide a detailed examination of volatility in crude oil prices and in other energy prices. Narayan and Narayan (2007) model oil price volatility and find that oil price performance in the daily data changes over short periods of time.
} 
The stationarity of the variables in the model is investigated by conducting Augmented Dicky-Fuller (ADF), Phillips-Perron (PP) and Kwiatkowski-Phillips-Schmidt-Shin (KPSS) tests for each series, the natural logarithm of oil production, aggregate demand, natural logarithm of real oil price, and real stock market returns. Test results are reported in Table 1. We find that we cannot reject the null hypothesis, based on the ADF test, that the variables in levels in Panel A of Table 1, oil supply and real price of oil, contains a unit root at the $1 \%$ significant level. This is also expected by the Phillips-Perron test that has the same power properties as the ADF test. Because both tests lack power it is possible that the failure to reject the null in one case is simply a type II error. Employing two tests with the same power and size properties will not enhance the properties of either and it could be argued that the ADF Generalised Least Squares test might be more powerful. However, failure to reject the null in this one variable is not decisive for the model. The KPSS has the null hypothesis that the series is stationary. The KPSS test rejects the hypotheses that all the variables in the oil market are stationary at the $5 \%$ significant level. In contrast, the ADF, PP and KPSS tests, shown in Panel B of Table 1, for each time-series in first differences reject the hypothesis containing a unit root at the $1 \%$ significant level.

A co-integration analysis between variables is performed to establish the validity of a VAR model rather than a structural VECM for the analysis of the oil price market. We conduct co-integration tests based on the methodology of Johansen and Juselius (1990) for the variables in the global oil market: world oil production, global real economic activity, and real price of oil. Table 2 reports the test results for co-integration. Both the eigenvalue statistics and the trace test statistics show that a long-run relationship does not exist among the three jointly determined 
variables in the oil market. These results are consistent with Apergis and Miller (2009) who investigate the co-integration relationship in the oil market for eight countries. ${ }^{8}$

\section{Empirical results}

\subsection{Evidence on parameter evolution}

We show evidence on how the parameters of the model have changed over time. From the mixture innovation specification we obtain probabilities of a break at each point in time. Presenting all posterior probabilities of jumps analytically for each parameter and each time period is not possible. Table 3 presents the average probabilities of a break over the whole sample period $t=1, \ldots, T$. The posteriors of the transitions probabilities of the three parameters, $\alpha_{t}, \log \sigma_{t}$ and $a_{t}$, are provided in Table 3. The value for $\alpha_{t}$ shows the gradual evolution of regression coefficients (i.e., a break of $\alpha_{t}$ to occur once per 4 months given a transition probability 0.281 ). The values for variance-covariance matrix elements $a_{t}$ and $\log \sigma_{t}$ above 0.9 indicate the high probability of change at each point of time in our time-varying parameter structural VAR model. Koop et al. (2009) and Korobilis (2013) have similar findings of time variation in all of the parameters in their mixture innovation time-varying parameter VAR models of the transmission of U.S. monetary policy.

Figure 3 presents the posterior means of coefficients of each variable with lag 1 , for the simplicity, in the real stock return equation to show the time-varying nature of parameters; that is the coefficients of the lag of oil supply $\left(\Delta \operatorname{prod}_{t-1}\right)$, aggregate demand $\left(\Delta r e a_{t-1}\right)$, real price of oil $\left(\Delta r p o_{t-1}\right)$ and real return $\left(r e t_{t-1}\right)$ in the fourth equation in the structural VAR model. There does seem to be some movement in the coefficients of $\left(\Delta r e a_{t-1}\right)$ and of $\left(\Delta r p o_{t-1}\right)$ over time. In the

\footnotetext{
${ }^{8}$ Haldrup and Nielsen (2006) argue that a regime switching model is especially attractive in forecasting electricity prices. Haldrup et al. (2010) show the long run convergence of electricity prices is a property following from regime switching rather than a conventional error correction mechanism.
} 
real stock return equation, the posterior coefficient of global real economic activity has declined since the late 1990s and that of oil price driven by oil-market specific demand shocks has fluctuated, being relatively high before 1988 and lower afterwards, especially from 1995 to 2001 and since 2006. The posterior coefficients of global oil production and of real return in the real stock return equation have remained stable.

Figure 4 shows the posterior means of simultaneous effects among endogenous variables in the structural VAR model (7); that is the posterior means of non-zero and non-one elements of the lower triangular matrix $A_{t}$ over time. It is important to notice that allowing the matrix $A_{t}$ to vary over time is crucial for our time varying structural VAR model. All plots in Figure 4 fluctuate substantially over time, indicating that an innovation to oil supply and demand prices has a time-variant effect on real oil prices in U.S. and U.S. real stock returns. The simultaneous interactions among variables are fundamental, because we construct the structural VAR representation of the model (7) through the relationship $\varepsilon_{t}=A_{t}^{-1} \Sigma_{t} u_{t}$, after the reduced-form VAR model (1) is consistently estimated.

Figure 5 plots the posterior means of standard deviations of errors of each equation in the structual VAR model (7); that is the posterior means of the square root of the diagonal elements of $H_{t}$. The posterior mean of the standard deviation of residuals shows the volatility of exogenous shocks. Figure 5 indicates significant variation in volatility in the equations of oil supply, aggregate demand, precautionary demand, and real return over time.

In the global real economic activity equation the standard deviation of residuals has fluctuated over time, reaching a forty year peak during the GFC and remaing high since. The standard deviation of residuals in the oil-market specific demand equation has been rising since the mid-1980s with peak value during the GFC. The standard deviation of residuals in the global 
oil production equation is smaller since the mid-1990s than before. The standard deviation of residuals in the real return equation has fluctuated over time with relatively large values since the GFC, but that is not out of line with that in the 1970s.

The substantial variation in the heteroskedastic VAR is consistent with major change in the shocks in oil and stock market over time. We investigate whether these changes have important implications for the effect of oil prices on real stock return through the analysis of impulse response functions in the next section.

\subsection{Time-varying effects of oil supply and demand shocks on real oil prices}

In this section we report results from the time-varying structural VAR model (7) of the responses of the real oil price to shocks from the global crude oil market at each point in time. The evolution of the median of the cumulative responses of real oil prices in 0-month (simultaneous responses), 3-month, 12-month and 24-month (long run responses) are shown between 1973:07 and 2012:12 in Figure 6. The impact response of real oil prices to one percent permanent increase in oil supply disruption is close to zero before 1983, increases substantially up to one percent during the Gulf War in 1990-1991, and become relatively flatter and close to zeros after 2005. The cumulative response of real oil prices to global aggregate demand shock has been relatively small before 1985, increased dramatically during the Great Moderation between the late 1980s and the early 2000s, and reached its peak during the GFC. The fluctuation of real oil prices is mainly contributed to oil market-specific demand shocks. For example, the positive effect is about two percent and increases steadily up to about 3.5 percent in 2012. These results are consistent with the finding in Kilian (2009) for the impact of oil price shocks on real prices of oil in U.S. over 1973:01-2006:12. The effect varies from episode to episode and depends on the underlying source of the price increase. 


\subsection{Time-varying structural VAR analysis of real stock return to oil shocks}

In this section we utilize the time-varying structural VAR model (7) to investigate the responses of real return to supply and demand side shocks in the crude oil market. To calculate the impulse responses of the U.S. real stock return to oil price shocks for each month, we run the MCMC algorithm executed 15,000 times, with the first 10,000 draws discarded as burn-in iterates. We normalize the dynamic effects of oil price shocks as one percent permanent increase on the impact of real stock return at each point in time. Baumeister and Peersman (2013b) argue that the conventional responses of the endogenous variables to one standard deviation shocks correspond to a different-sized shock at each point in time in the time-varying structural VAR model. We need to consider the scale of the impulse response functions over time in order to compare the economic consequences across episodes.

\subsubsection{Impulse response functions}

The evolution of the median of the cumulative responses of stock real return in 0 -month (simultaneous responses), 3-month, 12-month and 24-month (long run responses) are shown between 1973:07 and 2012:12 in Figure 7. First, the correlation between simultaneous and long run responses to three oil price shocks are high, in that their upward/downward sloping trend are similar at each point in time. Second, the response of real stock returns to oil price shocks is often gradual, in the sense that it takes time for the real return response to reach the long run response level upon an oil shock. It is often the case that the real return responses reach approximately the same level after 12 months.

In Figure 7 we plot the reaction of real stock return to the global oil supply shocks in the first panel. The impact response of the real return to one percent permanent increase in oil suppy is negative before 1975, close to zero in 1976 and fluctuates thereafter, becoming relatively 
flatter and close to zeros after 1985. The cummulative response of US real stock return to an oil supply shock has been relatively small at all monthly horizons since the mid-1990s.

The cumulative responses of real stock returns to aggregate demand shocks are presented in the second panel of Figure 7. The positive cummulative response of US real stock return to a global aggregate demand builds up over twelve months and then persists relatively unchanged up to 24 months. The responses of real stock return to one percent permanent increase in oil marketspecific demand are shown in the third panel of Figure 7. The negative cummulative response of US real stock return to a positive oil market-specific demand shock, builds up (in absolute value) over three months and then persists relatively unchanged for 24 months. The correlation between simultaneous and subsequent cummulative responses to oil market-specific demand shock is high.

\subsubsection{Variance decomposition}

The contributions of structural oil price shocks to real stock return variation in the U.S. over 1973:7 - 2012:12 are reported in Figure 8. The contribution of oil supply shocks to real stock return variation in the US after 24 months has trended downward over time from $17 \%$ in 1973 to 5\% in 2012, in line with relatively unchanging oil supply coefficients in the real stock return equation and declining standard deviation of residuals in the global oil production equation.

The significant contribution of oil supply shocks to stock return variation in the early part of the sample before the mid-1990s is associated with a large increase in the real oil price and a significant increase in stock price volatility following major geopolitical events. As noted in Hamilton (2013), these episodes include the OPEC oil embargo of 1973-1974, the Iranian revolution of 1978-1979, the Iran-Iraq War initiated in 1980, and the first Persian Gulf War in 
1990-1991. The reduced contribution of oil supply shocks to stock return variation in the later part of the sample is related to the finding in Lee et al. (2011) that more recent geopolitical events, such as Afghan War and the Iraq War, are not associated with a rise in the oil shock/stock price volatility variable.

The contribution of oil-market specific demand price shocks to real stock return variation gradually rose unevenly from the order of $5 \%$ in the mid-1970s to about $15 \%$ in 2007 , with a subsequent decline. The rise in contribution to real stock return variation up until 2007 is in line with the increase in the standard deviation of residuals in the oil-market specific demand equation since the mid-1980s.

The contribution of shocks to global real economic to real stock return variation fluctuated in the 5\% to $12 \%$ range from 1973-2008, before rising steeply to $22 \%$ in 2009 and remaining above $17 \%$ over $2009-2012$. This is consistent with sharply higher standard deviation of residuals in the global aggregate demand equation during and following the GFC.

Consistent with the variance decomposition results in Figure 8, the reaction of real stock return to the structural oil price shocks in Figure 7 suggests that since the GFC, oil marketspecific demand shocks are not as important for real return as before the GFC. In contrast, global aggregate demand shocks have become relatively more important in influencing real stock return since the GFC than before.

The structural oil shocks driving the global crude oil market together account for $25.7 \%$ of the long-run variation in U.S. real stock returns. In the time-varying parameter VAR model, oil market-specific demand shocks, global aggregate demand shocks, and oil supply shocks account for $9.1 \%, 8.3 \%$, and $8.3 \%$, respectively, of the long-run variation in U.S. real stock returns. This compares with results in Kilian and Park (2009) for which oil market-specific 
demand shocks, global aggregate demand shocks, and oil supply shocks account for $10.5 \%, 5.1 \%$, and 6.4\%, respectively, of the long-run variation in U.S. real stock returns.

\subsection{Model robustness}

\subsubsection{Alternative priors}

We set the priors for the initial states of the time-varying coefficients $\alpha_{t}$, simultaneous relations $a_{t}$ and $\log$ standard errors $\log \left(\sigma_{t}\right)$ to be normally distributed with mean 0 and very large variance $\left(10^{6}\right)$ indicating a relatively noninformative prior for each elements of the parameters in order to establish the robustness. The priors for the hyperparameters of their error covariance matrices are assumed to be distributed as independent inverse-Wishart with relatively large degree of freedom parameters.

Table 4 Panel A presents the posteriors of the probability of change in $k_{1}, k_{2}$ and $k_{3}$ for the three parameters of interest $\alpha_{t}, \log \sigma_{t}$ and $a_{t}$, respectively, that are estimates of three transitions probabilities $p_{1}, p_{2}$, and $p_{3}$. All the values are above 0.4 confirming that there is high probability that all three sets of parameters are likely to change at each point of time in our timevarying parameter VAR model. These point estimates still indicate gradual evolution of the timevarying parameter VAR than a small number of abrupt breaks (probability closer to zero) or extremely large number of breaks where the parameters are allowed to change with each new observation (a random walk and probability one).

To further verify the above results we consider the few breaks prior which expresses extremely strong views that the transition probabilities are near zero. The Beta prior of the form,

$p_{j} \operatorname{Beta}(0.1,1), j=1,2,3$, is then placed on the hyper-parameters $k_{j t}, j=1,2,3$, respectively, to control the prior belief about the number of breaks through a relatively informative choice. In 
the case of $\alpha_{t}$, even though the results in Panel B of Table 4 show that the priors have some effects, we still find that gradual evolution of coefficients. These results using different priors confirm evidence of parameter change that is greatest for $\log \left(\sigma_{t}\right)$, but is still appreciable for $\alpha_{t}$ and $a_{t}$. Additionally we also investigate the impulse response functions by setting different lags in the VAR model. It turns out the results are very similar.

\subsubsection{Effects of oil price shocks on daily stock returns}

To establish the robusteness of the result that the intensity of the oil shock effects on stock returns vary drastically from one episode to the next in the monthly data, this subsection examines how oil price shocks affect the daily stock returns. ${ }^{9}$ We utilize the daily spot oil price from the U.S. Department of Energy as a proxy of world daily oil price. The daily stock market return for the U.S. is from daily returns of aggregate U.S. stock market indices drawn from CRSP. The daily sample period is from March 30, 1983 to December 31, 2012 and the observations in 1983 are used as a training sample.

We follow the standard approach in its simplest form to estimate the responses of macroeconomic aggregate to the oil price shocks (e.g., Lee and Ni (2002)). The variable in the VAR model includes the first difference of the natural logarithm of daily oil prices and the daily U.S. stock returns. The resulting estimates of effects on the stock returns represent the consequences of a weighted average of predetermined oil demand and oil supply shocks.

The contributions of oil price shocks to the U.S. daily stock return variation over 1984 2012 are reported in Figure 9. The contribution rises following the Iran-Iraq War initiated in 1980, increases sharply during the first Persian Gulf War over 1990 - 1991, moves unevenly between late 1991 to early 2008, and grows markedly during the GFC in 2008 - 2009 with very

\footnotetext{
${ }^{9}$ We thank a referee for pointing out that the main changes are omnipresent in the high frequency data.
} 
large fluctuation. These results confirm the importance of time varying effects of oil price shocks on the U.S. stock market returns in daily data as well as in monthly data.

\subsubsection{International evidence}

In this subsection we present the international evidence that an oil price shock has a significant contribution to the real stock return variation in Europe, a net importer of crude oil, and in Canada, an energy-exporting country. In the analysis the price of Brent crude oil is a proxy of world oil price, and the stock market indices are TSEurofirst 300 in Europe and S\&P/TSX Composite in Canada. ${ }^{10}$ World oil prices and aggregate stock returns are deflated by Europe/Canada CPI, respectively, to obtain the real variables. The sample period is determined by the availability of the Brent crude oil price starting in January 1990. We utilize a training sample, the first 5 years of data, 1990:01-1994:12, to calibrate the key prior hyperparameters.

Figure 10 reports the forecast error variance decomposittions of European real stock returns in 24 months. The shock effects of real aggregate demand account for about $15 \%$ of the volatility in the European real stock returns in 1995 and increases gradually and significantly to more than 22\% in 2012. This similar to the results for shocks to real aggregate demand and US real stock returns over 1995-2012 (but evener). The contributions of oil supply and oil-market specific demand shocks to the European real stock returns each decrease gradually from 1995 to 2012, and both effects for European real stock returns are somewhat larger the comparable effects for US real stock returns.

The forecast error variance decompotions of Canadian real stock returns in 24 months are presented in Figure 11. The contributions of three oil price shocks to the real stock returns in Canada are quantitatively similar to the results obtained in Europe from 1995 to 2012. The

\footnotetext{
${ }^{10}$ FTSEurofirst 300 Index represents 300 largest companies ranked by market capitalization in Europe. S\&P/TSX Composite is an index of the stock prices of the largest companies and comprises about $70 \%$ of market capitalization for all Canadian-based companies.
} 
contribution of shocks to real aggregate demand to real stock return variation is similar to the results obtained for the US, fluctuating in the 12\% to 18\% range from 1995-2008 before rising steeply to $21 \%$ in 2009 and remaining above $18 \%$ over 2009-2012. In recent years, the effects of real aggregate demand shocks on volatility in Canadian, European and US stocks are similar to one another at around 20\%. The effects of oil supply and oil-market specific demand shocks on volatility in Canadian and European real stock returns are larger than the effects on the volatility of US stocks and all less than the effects of real aggregate demand shocks on volatility.

\section{Conclusion}

Study of the important connections between the oil and financial markets has generated a substantial body of work. Improved understanding of these relationships has potentially significant implications for better understanding of the real and financial economy. Much of the literature has noted that the key connections between oil and financial markets and the real economy have been changing over time. A substantial literature on the oil price-stock return relationship notes structural shifts, time varying volatility, and nonlinearity over time. We believe that it is crucial in assessing the effect of an oil price shock that the source of the shock be identified and that the sources of time variation are investigated for both the coefficients and the variance covariance matrix of the innovations.

This paper examines the effects of oil price shocks on stock market real return using a mixture innovation time-varying parameter VAR model. We investigate the impact of oil price shocks on the U.S. stock market. It is found that oil price shocks contain information for forecasting real stock return. It is found that coefficients and the nature of shocks have changed over time. In the real stock return equation, the posterior coefficients of global real economic activity and of oil price driven by oil-market specific demand are smaller in the last part of the 
sample. This contrasts with the standard deviation of residuals in the global real economic activity and oil-market specific demand equations. The standard deviation of residuals in the global real economic activity equation reached a forty year peak during the GFC and remained high since. The standard deviation of residuals in the oil-market specific demand equation have been rising since the mid-1980s with peak value during the GFC. The standard deviation of residuals in the global oil production equation are smaller since the mid-1990s than before.

The contribution of shocks to global real economic activity to real stock return variation rose sharply to $22 \%$ in 2009 (and is $17 \%$ over 2009-2012) after fluctuating in the $5 \%$ to $12 \%$ range from 1973-2008. This is consistent with sharply higher standard deviation of residuals in the global aggregate demand equation during and following the GFC. The contribution of oilmarket specific demand price shocks to real stock return variation gradually rose unevenly from the order of 5\% in the mid-1970s to about 15\% in 2007, with a subsequent decline. This is in line with the increase in the standard deviation of residuals in the oil-market specific demand equation since the mid-1980s. The contribution of oil supply shocks to real stock return variation in the US after 24 months has trended downward over time from 17\% in 1973 to 5\% in 2012. Following the global financial crises aggregate demand shocks have become much more important in explaining real stock return in the US.

\section{References}

Abhyankar, A., Xu, B., Wang, J., 2013. Oil price shocks and the stock market: evidence from Japan. The Energy Journal 34, 199-222.

Aloui, R., Hammoudeh, S., Nguyen, D.K., 2013. A time-varying copula approach to oil and stock market dependence: The case of transition economies. Energy Economics 39, 208-221.

Aloui, C., Nguyen, D.K., Njeh, H., 2012. Assessing the impacts of oil price fluctuations on stock returns in emerging markets. Economic Modelling 29, 2686-2695. 
Apergis, N., Miller, S.M., 2009. Do structural oil-market shocks affect stock prices? Energy Economics 31, 569-575.

Arouri, M.E.H., 2011. Does crude oil move stock markets in Europe? A sector investigation. Economic Modelling 28, 1716-1725.

Arouri, M.E.H., Rault, C., 2011. On the influence of oil prices on stock markets: Evidence from panel analysis in GCC countries. International Journal of Finance and Economics 3, 242-253.

Arouri, M.E.H., Jouini, J., Nguyen, D.K., 2012. On the Impacts of Oil Price Fluctuations on European Equity Markets: Volatility Spillover and Hedging Effectiveness. Energy Economics 34, 611-617.

Barsky, R.B., Kilian, L., 2002. Do we really know that oil caused the great stagflation? A monetary alternative. NBER Macroeconomics Annual 2001 16, 137-198.

Baumeister, C., Peersman, G., 2013a. The Role of Time-varying Price Elasticities in Accounting for Volatility Changes in the Crude Oil Market. Journal of Applied Econometrics 28, 1087-1109.

Baumeister, C., Peersman, G., 2013b. Time-varying effects of oil supply shocks on the U.S. economy. American Economic Journal: Macroeconomics 5, 1-28.

Bauwens, L., Koop, G., Korobilis, D., Rombouts, J., 2014. The contribution of structural break models to forecasting macroeconomic series. Journal of Applied Econometrics, DOI: 10.1002/jae.

Blanchard, O. J., Gali, J., 2009. The Macroeconomic Effects of Oil Shocks: Why are the 2000s So Different from the 1970s? In: Gali, J., Gertler, M. (Eds.), International Dimensions of Monetary Policy. University of Chicago Press, 373-428.

Blanchard, O. J., and Riggi, M., 2013. Why are the 2000s So Different from the 1970s? A structural interpretation of changes in the macroeconomic effects of oil prices. Journal of the European Economic Association 11, 1032-1052.

Broadstock, D., Filis, G., 2014. Oil price shocks and stock market returns: New evidence from the United States and China. Journal of International Financial Markets, Institutions and Money 33, 417-433.

Carter, C.K., Kohn, R., 1994. On Gibbs sampling for state space models. Biometrika 81, 541553.

Chang, C.-L., McAleer, M., Tansuchat, R., 2013. Conditional correlations and volatility spillovers between crude oil and stock index returns. The North American Journal of Economics and Finance 25, 116-138. 
Chang, K.-L., Yu, S.-T., 2013. Does crude oil price play an important role in explaining stock return behavior? Energy Economics 39, 159-168.

Chen, N.F., Roll, R., Ross, S., 1986. Economic forces and the stock market. Journal of Business 59, 383-403.

Chen, S.-S., 2010. Do higher oil prices push the stock market into bear territory? Energy Economics 32 (2), 490-495.

Cogley, T., Sargent, T., 2001. Evolving post-world war II U.S. inflation dynamics. In: Bernanke, B.S., Rogoff, K. (Eds.), NBER Macroeconomics Annual, Vol. 16. MIT Press, Cambridge, MA, 331-388.

Cogley, T., Sargent, T., 2005. Drifts and volatilities: monetary policies and outcomes in the post WWII U.S. Review of Economic Dynamics 8, 262-302.

Cunado, J., de Gracia, F.P., 2014. Oil price shocks and stock market returns: Evidence for some European countries. Energy Economics 42, 365-377.

Degiannakis, S., Filis, G., Floros, C., 2013. Oil and stock returns: Evidence from European industrial sector indices in a time-varying environment. Journal of International Financial Markets, Institutions and Money 26, 175-191.

Degiannakis, S., Filis, G., Kizys, R., 2014. The effects of oil price shocks on stock market volatility: evidence from European data. The Energy Journal 35, 35-56.

Del Negro, M., Primiceri, G., 2014. Time varying structural vector autoregressions and monetary policy: A corrigendum. Federal Reserve Bank of New York Staff Reports, no. 619.

Durbin, J., Koopman, S., 2002. A simple and efficient simulation smoother for state space time series analysis. Biometrika 89, 603-616.

Efimova, O., Serletis, A., 2014. Energy markets volatility modelling using GARCH. Energy Economics 42, 264-273.

Elder, J., Serletis, A., 2010. Oil price uncertainty. Journal of Money, Credit and Banking 42, $1137-1159$.

Filis, G., Degiannakis, S., Floros, C., 2011. Dynamic correlation between stock market and oil prices: The case of oil-importing and oil-exporting countries. International Review of Financial Analysis 20, 152-164.

George, E. I., Sun, D., Ni, S., 2008. Bayesian stochastic search for VAR model restrictions. Journal of Econometrics 142, 553-580. 
George, E.I., McCulloch, R.E., 1997. Approaches for Bayesian variable selection. Statistica Sinica 7, 339-373.

Gerlach, R., Carter, C., Kohn, E., 2000. Efficient Bayesian inference in dynamic mixture models. Journal of the American Statistical Association 95, 819-828.

Giordani, P., Kohn, R., 2008. Efficient Bayesian inference for multiple change-point and mixture innovation models. Journal of Business and Economic Statistics 26, 66-77.

Guesmi, K., Fattoum, S., 2014. Return and volatility transmission between oil prices and oilexporting and oil-importing countries. Economic Modelling 38, 305-310.

Haldrup, N., Nielsen, F.S., Nielsen, M.Ø., 2010. A vector autoregressive model for electricity prices subject to long memory and regime switching. Energy Economics 32, 1044-1058.

Haldrup, N. Nielsen, M.Ø., 2006. A regime switching long memory model for electricity prices. Journal of Econometrics 135, 349-376.

Hamilton, J.D., 2009. Causes and consequences of the oil shock of 2007-08. Brookings Papers on Economic Activity, Spring, 215-261.

Hamilton, J.D., 2013. Historical Oil Shocks. In: Parker, R.E., Whaples, R.M. (Eds.), The Routledge Handbook of Major Events in Economic History. New York: Routledge Taylor and Francis Group, 239-265.

Inchauspe, J., Ripple, R.D., Trück, S., 2015. The dynamics of returns on renewable energy companies: A state-space approach. Energy Economics 48, 325-335.

Jiménez-Rodríguez, R., 2015. Oil price shocks and stock markets: testing for non-linearity. Empirical Economics 48, 1079-1102.

Jiménez-Rodríguez, R., Sanchez, M., 2005. Oil price shocks and real GDP growth, empirical evidence for some OECD countries. Applied Economics 37, 201-228.

Jochmann, M., Koop, G., Leon-Gonzalez, R., Strachan, R.W., 2013. Stochastic search variable selection in vector error correction models with an application to a model of the UK macroeconomy. Journal of Applied Econometrics 28, 62-81.

Jochmann, M., Koop, G., Strachan, R.W., 2010. Bayesian forecasting using stochastic search variable selection in a VAR subject to breaks. International Journal of Forecasting 26, 326-347.

Johansen, S., Juselius, K., 1990. Maximum Likelihood Estimation and Inference on Cointegration-with Applications to the Demand for Money. Oxford Bulletin of Economics and Statistics 52, 169-210.

Jones, C.M., Kaul, G., 1996. Oil and the stock markets. Journal of Finance 51, 463-491. 
Jouini, J., 2013. Stock markets in GCC countries and global factors: A further investigation. Economic Modelling 31, 80-86.

Kang, W., Ratti, R.A., 2013. Oil shocks, policy uncertainty and stock market return. Journal of International Financial Markets, Institutions and Money 26, 305-318.

Kilian, L., 2009. Not all oil price shocks are alike: disentangling demand and supply shocks in the crude oil market. American Economic Review 99, 1053-1069.

Kilian, L., Park, C., 2009. The impact of oil price shocks on the U.S. stock market. International Economic Review 50, 1267-1287.

Kilian L., Vega, C., 2011. Do energy prices respond to U.S. macroeconomic news? A test of the hypothesis of predetermined energy prices. The Review of Economics and Statistics 93, 660-671.

Kim, S., Shephard, N., Chib, S., 1998. Stochastic volatility: likelihood inference and comparison with ARCH models. Review of Economic Studies 65, 361-393.

Koop, G.. Korobilis, D., 2010. Bayesian Multivariate Time Series Methods for Empirical Macroeconomics. Foundations and Trends in Econometrics 3, 267-358.

Koop, G., Leon-Gonzales, R., Strachan, R., 2009. On the evolution of the monetary policy transmission mechanism. Journal of Economic Dynamics and Control 33, 997-1017.

Korobilis, D., 2013. Assessing the transmission of monetary policy using time-varying parameter dynamic factor models. Oxford Bulletin of Economics and Statistics 75, 157-179.

Lee, K., Kang, W., Ratti, R.A., 2011. Oil price shocks, firm uncertainty, and investment. Macroeconomic Dynamics 15, 416-436.

Lee, C.-C., Zeng, J.-H., 2011. The impact of oil price shocks on stock market activities: Asymmetric effect with quantile regression. Mathematics and Computers in Simulation 81, 1910-1920.

Lee, K., Ni, S., 2002. On the dynamic effects of oil price shocks: A study using industry level data. Journal of Monetary Economics 49, 823-852.

Liu, Y., Morley, J., 2014. Structural evolution of the postwar U.S. economy. Journal of Economic Dynamics \& Control 42, 50-68.

Miller, J.I., Ratti, R.A., 2009. Crude oil and stock markets: Stability, instability, and bubbles. Energy Economics 31, 559-568.

Moya-Martínez, P., Ferrer-Lapeña, R., Escribano-Sotos, F., 2014. Oil price risk in the Spanish stock market: An industry perspective. Economic Modelling 37, 280-290. 
Nandha, M., Faff, R., 2008. Does Oil Move Equity Prices? A Global View. Energy Economics 30, 986-997.

Narayan, P.K., Narayan, S., 2007. Modelling oil price volatility. Energy Policy 35, 6549-6553.

Narayan, P.K., Narayan, S., Sharma, S., 2013. An analysis of commodity markets: what gain for investors? Journal of Banking and Finance 37, 3878-3889.

Narayan, P.K., Sharma, S.S., 2011. New evidence on oil price and firm returns. Journal of Banking and Finance 35, 3253-3262.

Narayan, P.K., Sharma, S.S., 2014. Firm return volatility and economic gains: The role of oil prices. Economic Modelling 38, 142-151.

Panopoulou, E., Pantelidis, T., 2015. Speculative behaviour and oil price predictability. Economic Modelling 47, 128-136.

Park, J., Ratti, R.A., 2008. Oil prices and stock markets in the U.S. and 13 European countries. Energy Economics 30, 2587-2608.

Phan, D.H.B., Sharma, S.S., Narayan, P.K., 2015a. Oil price and stock returns of consumers and producers of crude oil. Journal of International Financial Markets, Institutions and Money 34, 245-262.

Phan, D.H.B., Sharma, S.S., Narayan, P.K., 2015b. Stock return forecasting: Some new evidence. International Review of Financial Analysis 40, 38-51.

Primiceri, G.E., 2005. Time varying structural vector autoregressions and monetary policy. Review of Economic Studies 72, 821-852.

Rotemberg, J., Woodford, M., 1997. An optimization-based econometric framework for the evaluation of monetary policy. In: Bernanke, B.S., Rotemberg, J. (Eds.), NBER Macroeconomics Annual, Vol. 12, MIT Press, Cambridge, MA, 297-361.

Sadorsky, P., 1999. Oil price shocks and stock market activity. Energy Economics 21, 449-469.

Sim, N., Zhou, H., 2015. Oil prices, US stock return, and the dependence between their quantiles. Journal of Banking and Finance 55, 1-8.

Sims, C.A., 1980. Macroeconomics and reality. Econometrica 48, 1-48.

Sims, C., Zha, T., 2006. Were there regime switches in macroeconomic policy? American Economic Review 96, 54-81. 


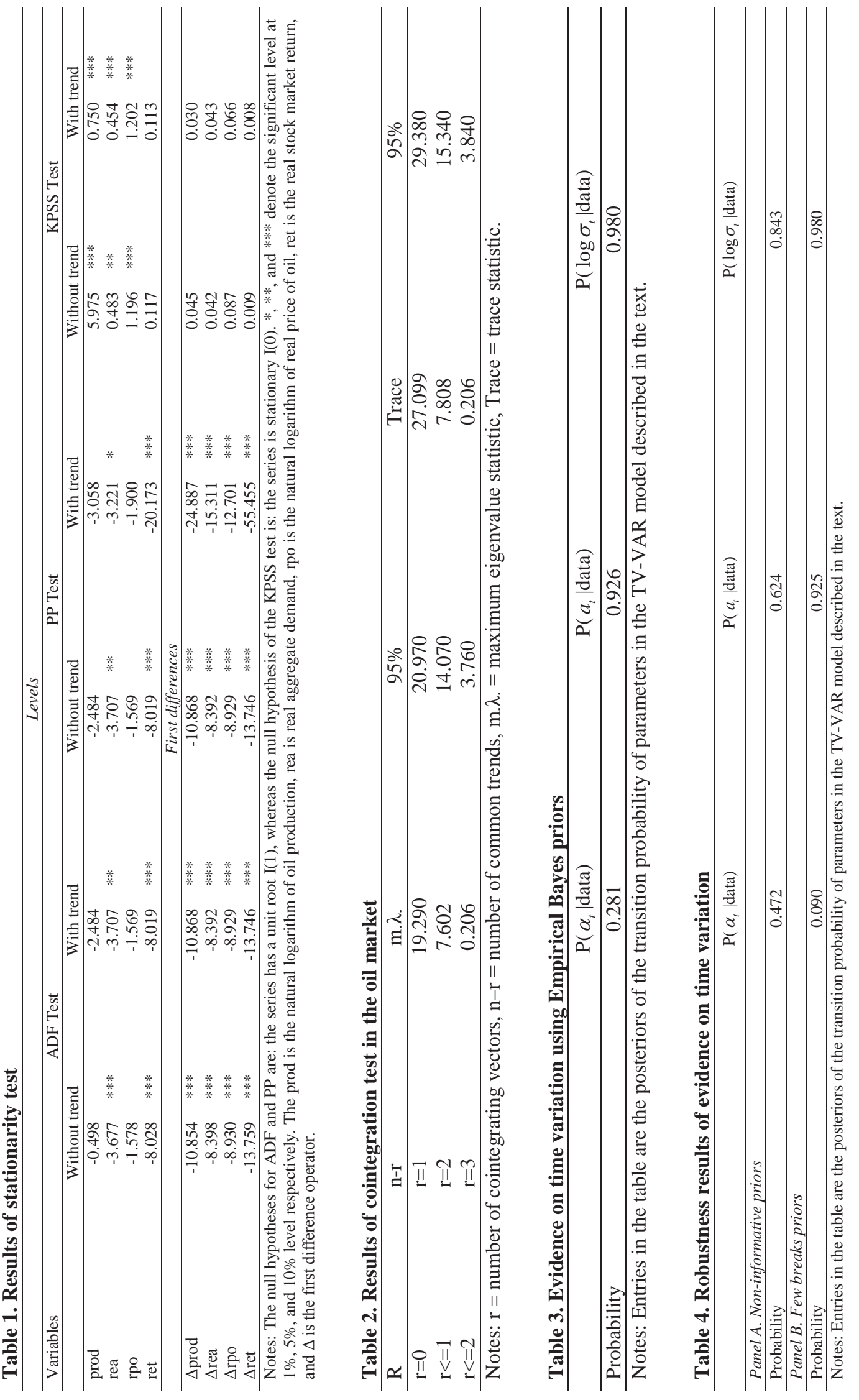



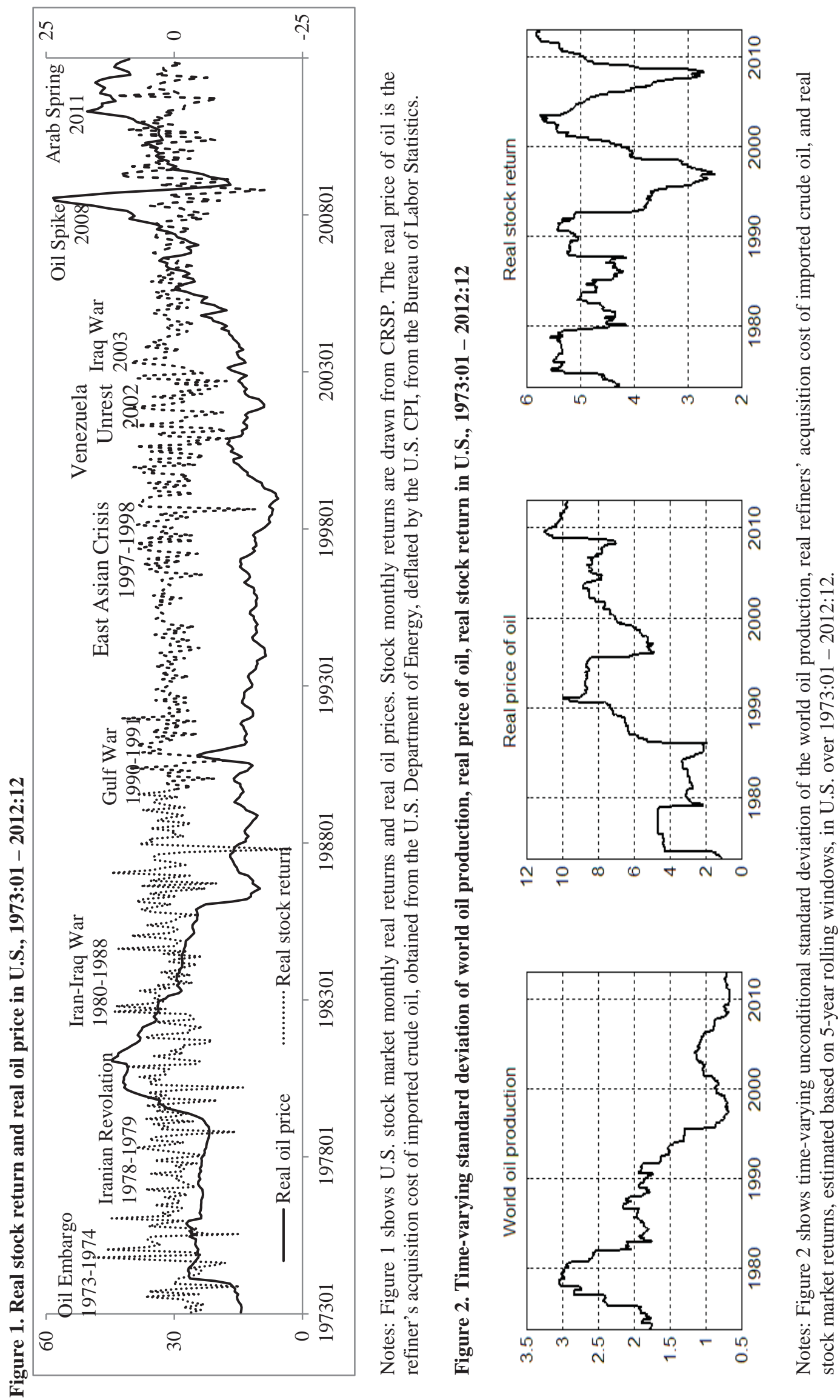


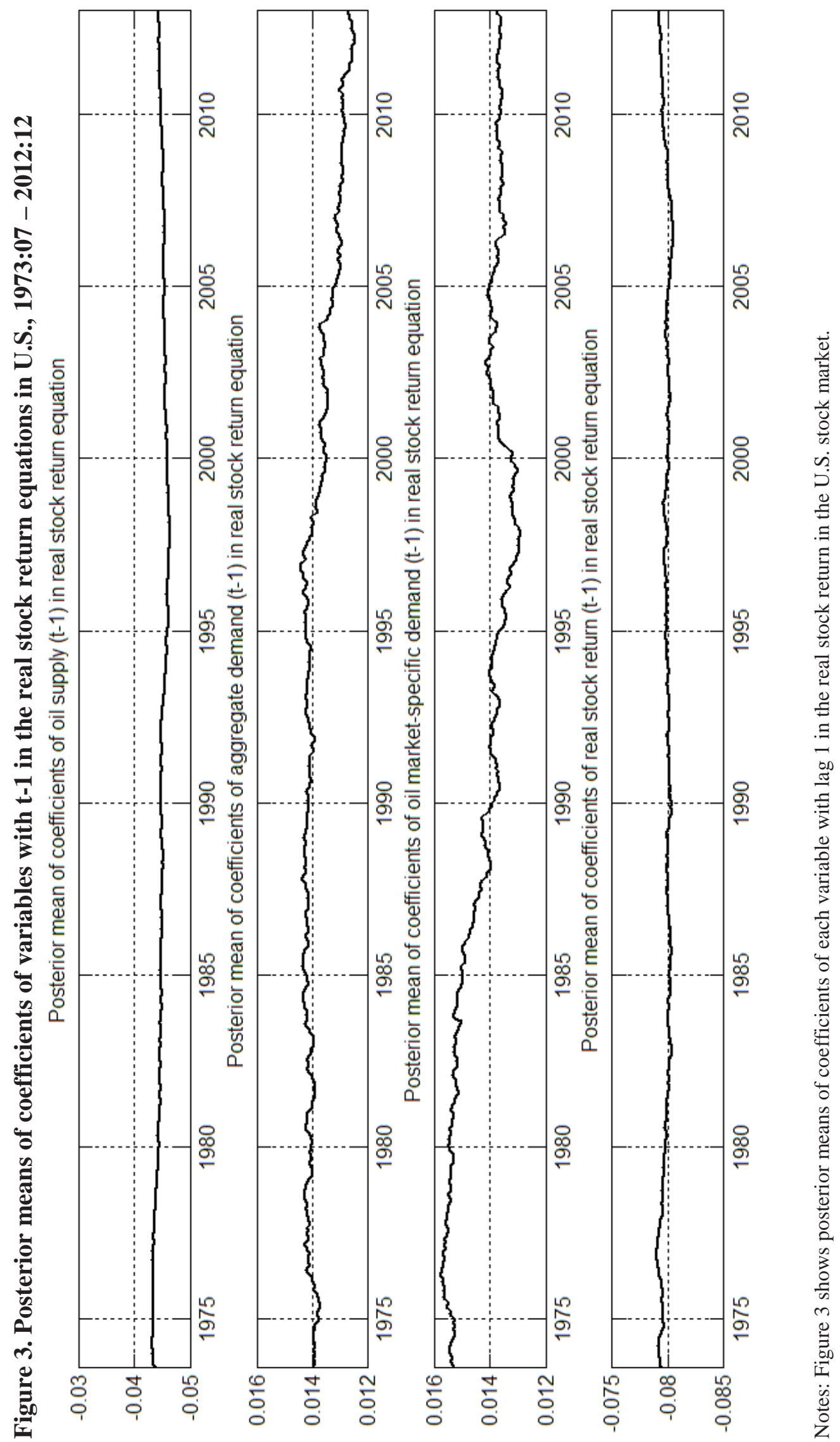




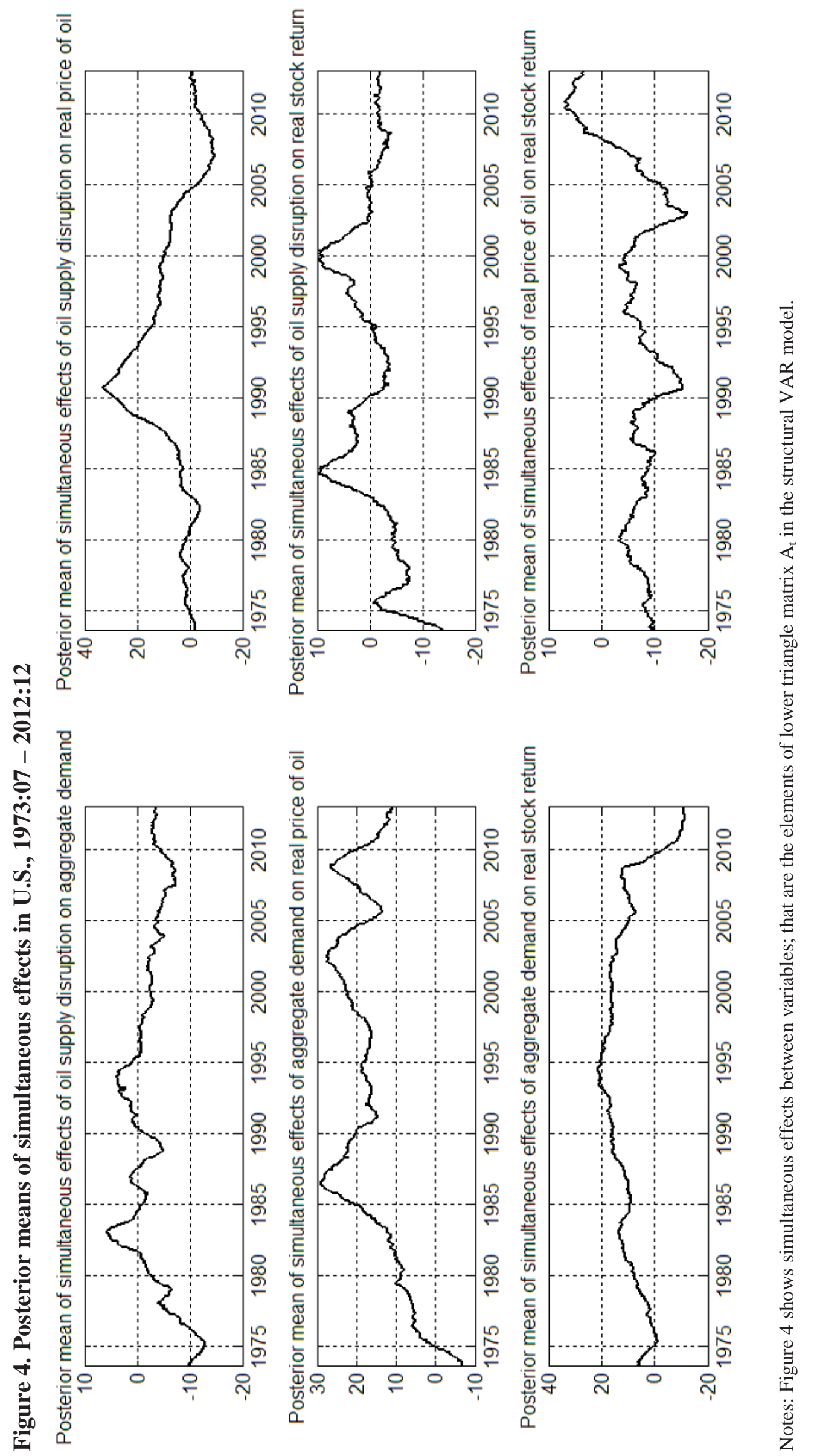




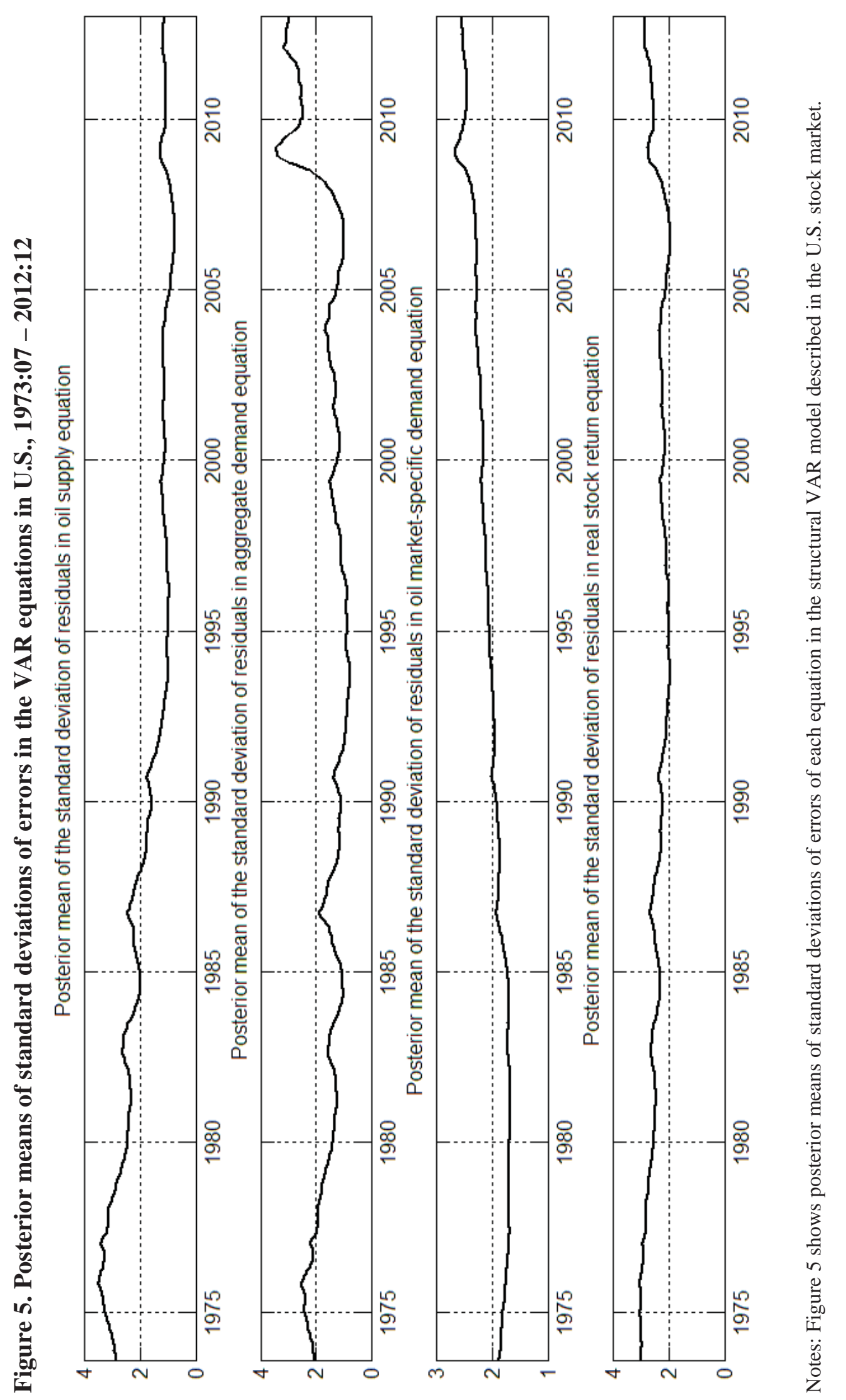




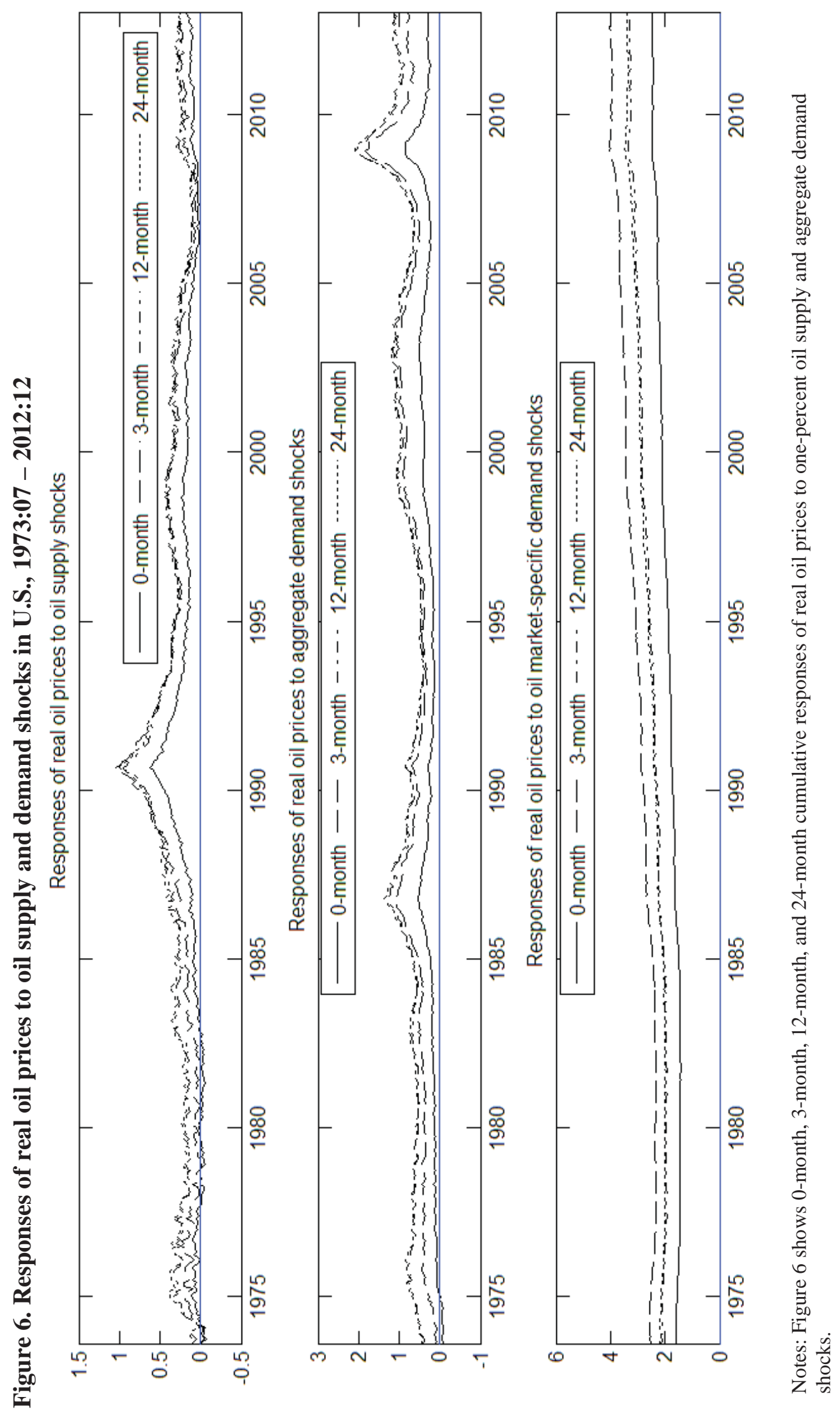




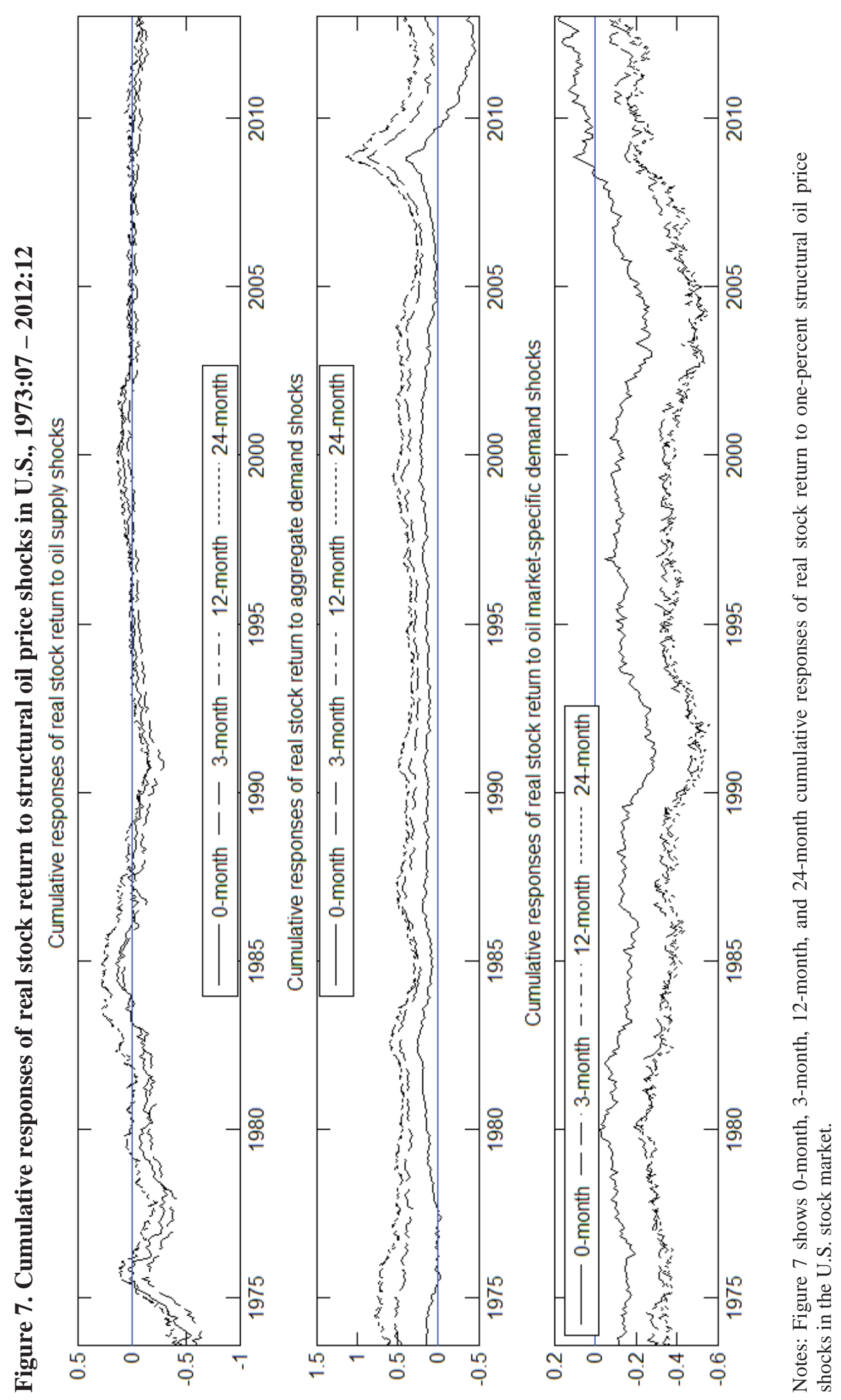




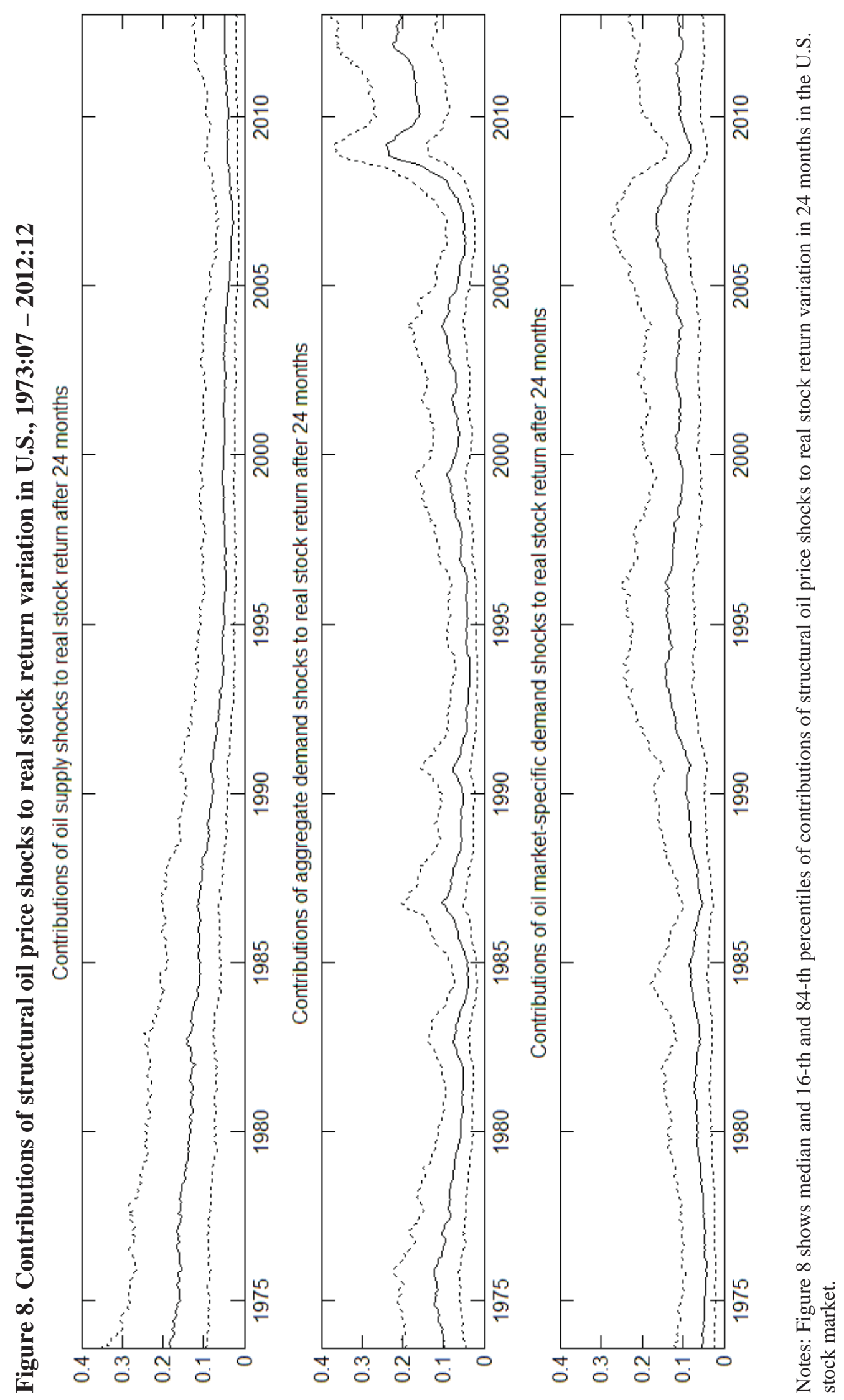




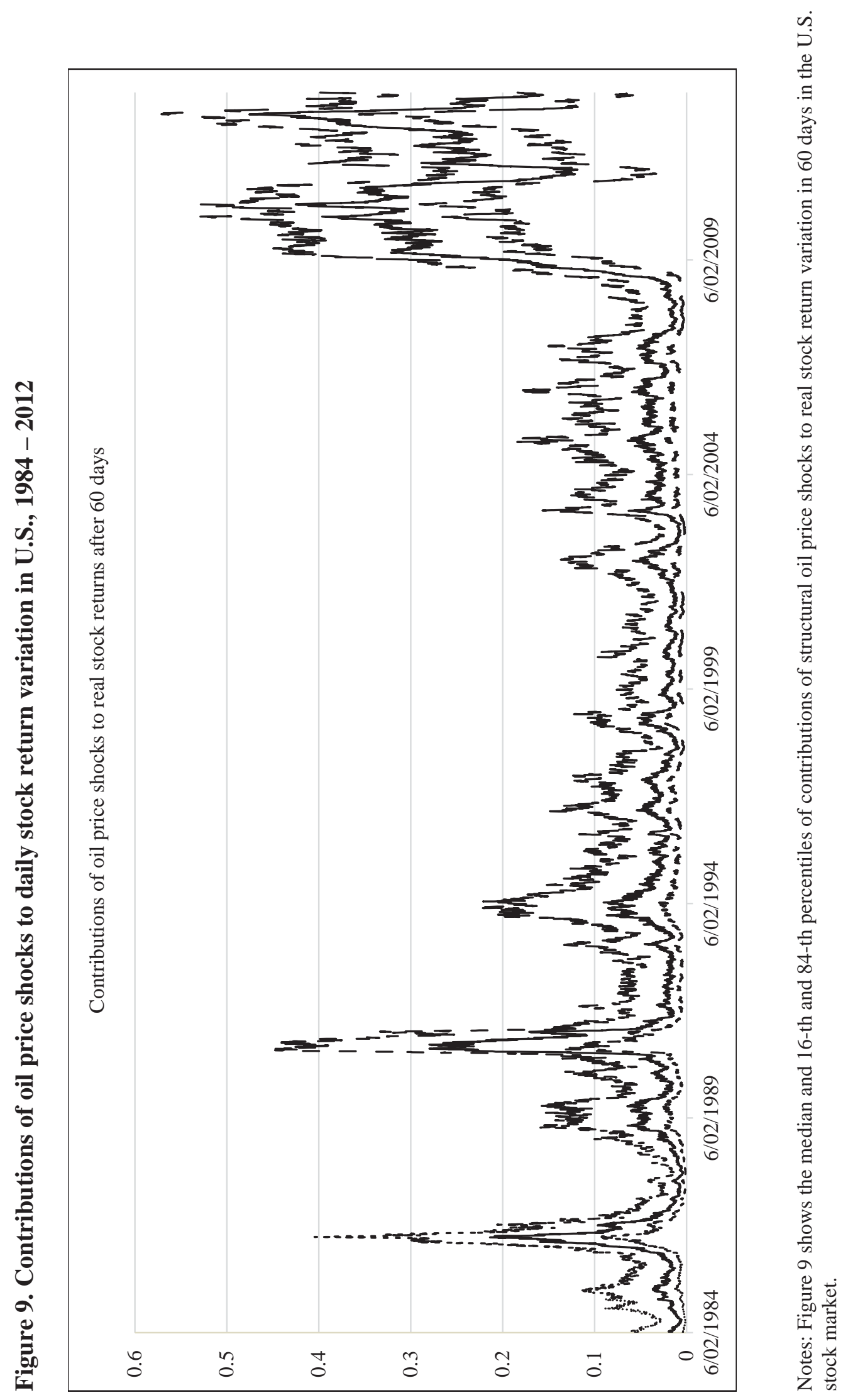




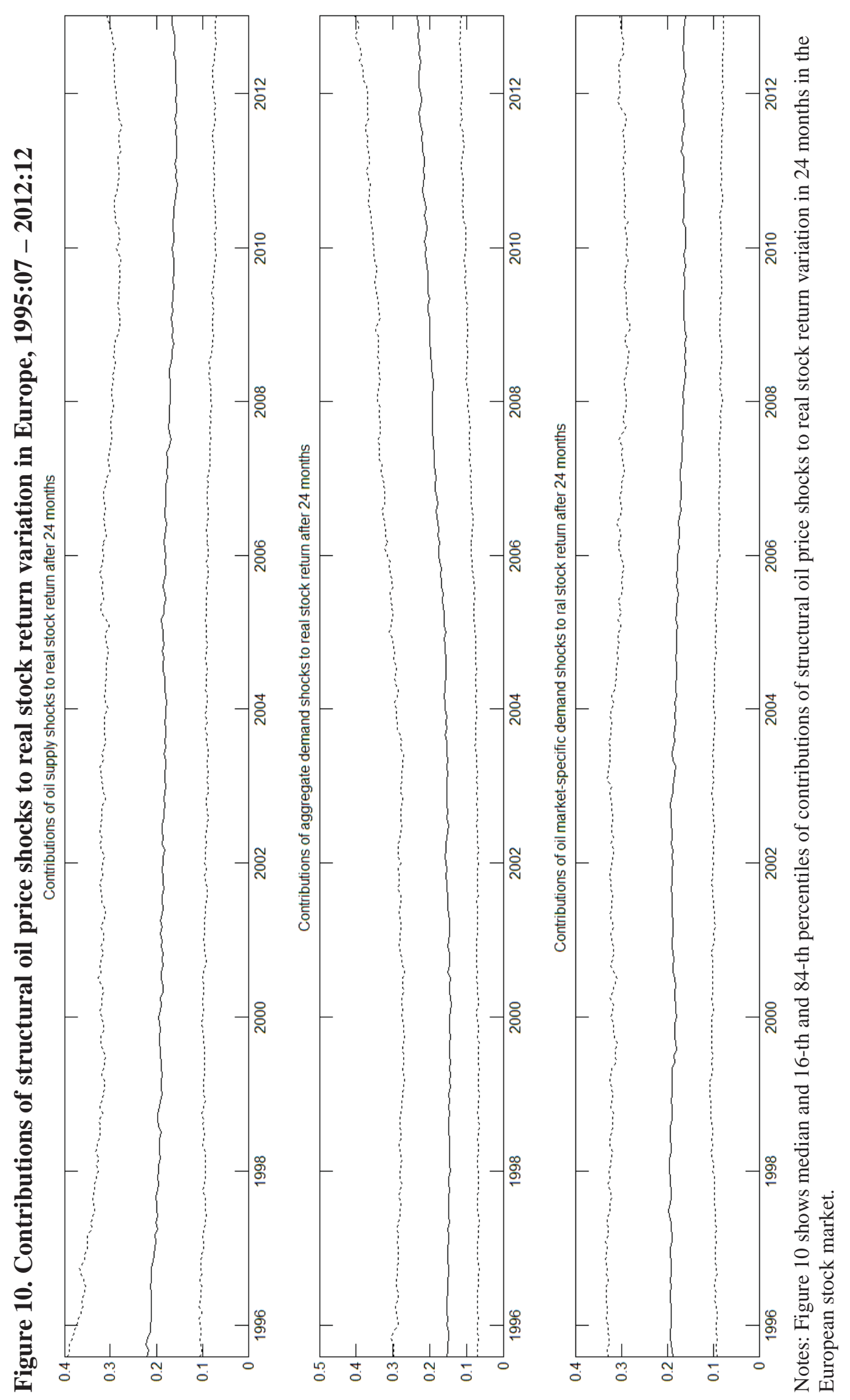




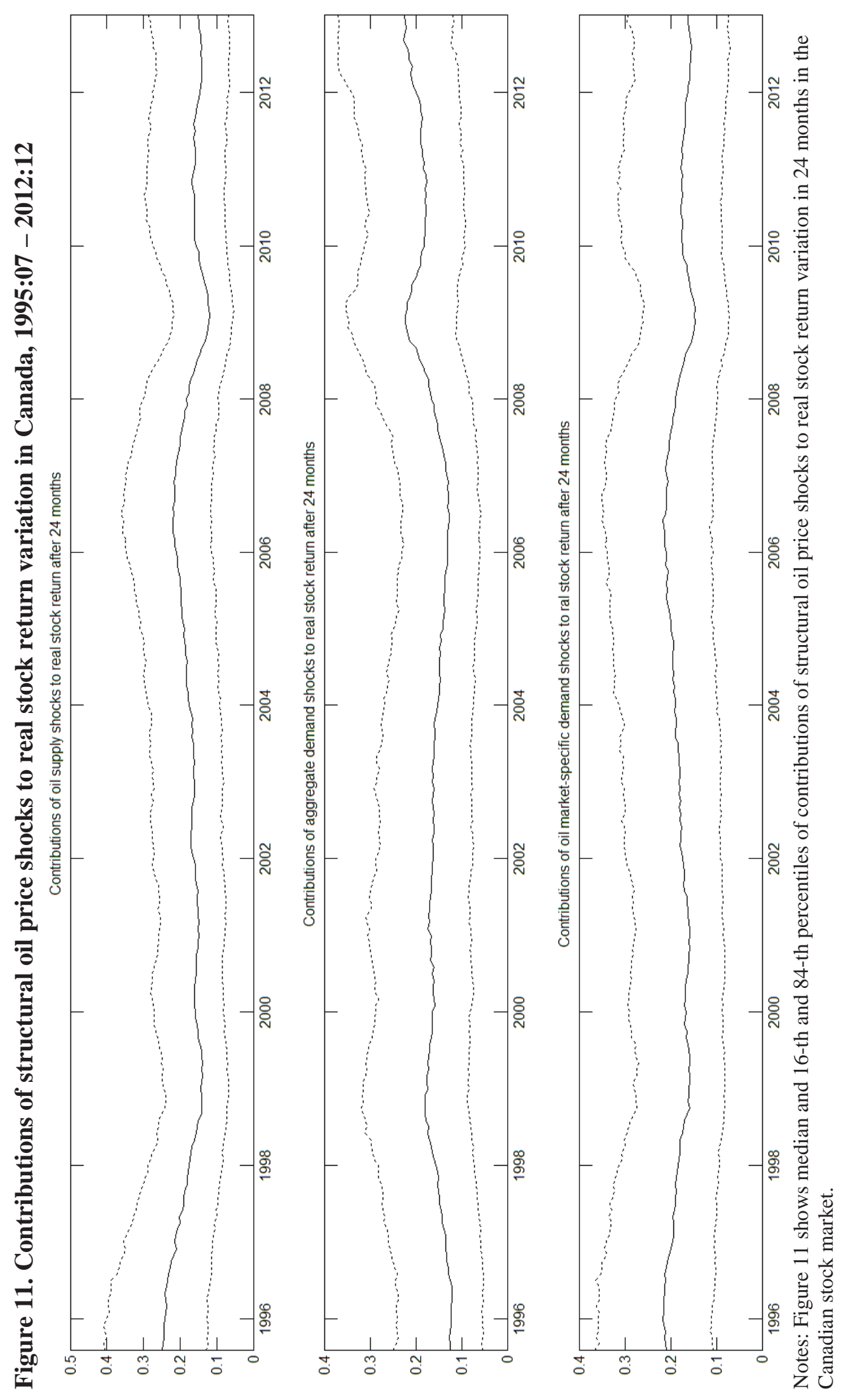

